\title{
Agencies in Technology Design: Feminist Reconfigurations
}

\author{
Lucy Suchman \\ Lancaster University
}

Agency is not an attribute but the ongoing reconfigurings of the world.

Barad 2003: 818

In this chapter I consider some new resources for thinking about how capacities for action are configured at the human-machine interface, informed by developments in feminist science and technology studies. While not all of the authors and works cited would identify as feminist, they share with feminist research - in my reading at least - a commitment to critical, but also reconstructive engagement with received conceptions of the human, the technological and the relations between them. Based on my own experience of the worlds of technology research and development, I argue that these reconceptualisations have implications for everyday practices of technology design.

Both reconceptualisations of the human-machine interface, moreover, and the practices of their realization are inflected by, and consequential for, gendered relations within technoscience and beyond. The ideas and examples that I discuss below are draw from science and technology studies (STS), feminist theory, new media studies and experiments in cooperative systems design, each of which is multiple and extensive in themselves and no one of which can be adequately represented here. My hope nonetheless is to trace out enough of the lines of resonant thought that run across these fields of research to indicate the fertility of the ground, specifically with respect to creative reconfigurations at the interface of human and machine.

One of the issues at stake here is the question of what counts as 'innovation' in science and engineering. This in itself, I will propose, is a gendered question insofar as it aligns with the longstanding feminist concern with the problem of who is recognized and who not in prevailing discourses of science and technology (see for example Suchman and Jordan 1989). Recent research on the actual work involved in putting technologies into use highlights the mundane forms of inventive yet taken for granted labor, hidden in the background, that are necessary to the success of complex sociotechnical arrangements. ${ }^{1} \mathrm{~A}$ central strategy in recognizing those labors is to decenter sites of innovation from singular persons, places and things to multiple acts of everyday activity, including the actions through which only certain actors and associated achievements

\footnotetext{
${ }^{1}$ For a case study of the design work involved in use, see Clement 1993. On the role of this kind of invisible labor in science more generally see Fujimura 1987, Shapin 1989, Star 1991, and for its relevance to system design see Schmidt and Bannon 1992.
} 
come into public view. At the same time, we need to ask how projects to reclaim creativity, invention and the like might themselves be reproductive of a, specific, cultural and historical preoccupation with these particular values. Must those not presently identified as creative be shown in fact to be inventors in order to be fully recognized? This question suggests that we need to pay close attention to the tensions and contradictions that arise when we adopt a strategy that distributes practices previously identified exclusively with certain people and places (for example, with privileged white men working in elite institutions of science and technology) across a wider landscape (one that includes women). In distributing those practices more widely, they are given correspondingly greater presence. A counter project, therefore, is to question the value placed on innovation itself. The aim is to understand how a fascination with change and transformation might not be universal, but rather specifically located and with particular political consequences for women, both in terms of the possibilities that are available to them, and the visibility of their already existing contributions.

\section{Re-examining binary oppositions}

Feminist research practices are distinguished by the joining of rigorous critique with a commitment to transformative engagement. Certain questions, while not exclusive to feminist research, are central for contemporary feminist scholars engaging with science and technology. STS scholars more broadly have traced the histories through which certain binary divisions emerged as foundational to modern science, including divisions of subject and object, human and nonhuman, nature and culture. Feminist scholars have drawn attention to the politics of ordering within such binary divisions, beginning with identifications of sex and gender. A starting observation is that in these pairings the first term typically acts as the privileged reference, against which the second is judged.

The question of difference outside of overly dichotomous and politically conservative oppositions is one that has been deeply and productively engaged within feminist and postcolonial scholarship. ${ }^{2}$ At least since Donna Haraway's famous intervention with respect to the figure of the 'cyborg' (1985/1991), feminist scholars have begun to embrace the inseparability of subjects and objects, 'natural' bodies and 'artificial' augmentations. The cyborg is a concept appearing first in the context of developments in cybernetics in the mid-twentieth century, materialized in their application to the U.S.-Soviet 'space race.' By the 1980s, due in no small measure to the popular imagery of film and science fiction, the cyborg had become a kind of icon of masculinist and military projects. Haraway's contribution was to propose that rather than simply rejecting the cyborg figure, feminists might actually reclaim it and explore its different possibilities. Among other things, she argued that the cyborg could represent the life-affirming and enabling possibilities of close couplings between people and machines. For it to do so, however, she urged that the study of those connections include consistent attention to the labors that are inevitably required in order for human-machine 
interactions to succeed. To the extent that those labors are obscured, humans disappear and artifacts are mystified.

The primary site for my own exploration of these questions has been research and development at the human-computer interface of. More specifically, my work since the 1980s has been concerned with the question of what understandings of the human, and more particularly of human action, is realized in initiatives in the fields of artificial intelligence and robotics (Suchman 1987, forth). Immersed in studies of symbolic interactionism and ethnomethodology, I came to the question of machine intelligence with an orientation to the primacy of communication, or interaction, to the emergence of those particular capacities that have come to define the human. This emphasis on sociality stood in strong contrast to prevailing models of the individual cognizer as the origin point for rational action. A growing engagement with anthropology and with STS expanded the grounds for my critique and underscored the value of close empirical investigations into the mundane ordering of sociomaterial practices. Initiatives in the participatory or cooperative design of information systems opened up a further space for pro-active experiments, during the 1990s, in the development of an ethnographically informed and politically engaged design practice (Blomberg et al., 1996; Suchman 2002 a,b). Most recently, my frame of reference has been further expanded through the generative theorizing and innovative research practices of feminist scholarship. Within this feminist frame, the universal human cognizer is progressively displaced by attention to the specificities of knowing subjects, multiply and differentially positioned, and variously engaged in reiterative and transformative activities of collective world-making.

\section{Subjects and Objects}

Within science and technology studies, the relation of persons and things been most famously addressed in Actor Network Theory's call for a "generalized symmetry" in analyses of human and nonhuman contributions to social order (see Ashmore et al 1994). For those writing within the Actor Network tradition and its aftermath, agency, or our capacity for action as humans, is reconceptualised from something inherent in us as individual actors, to an effect of our intimate relations to nonhuman things.. A rich body of empirical studies have further specified, elaborated, and deepened the senses in which human agency is always inextricably tied to the specific sociomaterial arrangements of which we are part.These studies provide compelling empirical demonstration of how capacities for action can be reconceived on foundations quite different from those of an Enlightenment, humanist preoccupation with the individual actor living in a world of separate things. Insofar as we see the politics of technology to be based in fundamental assumptions about where agency is located, and whose agencies matter, these approaches have at least the potential to work as powerful allies to feminist projects. In particular, these scholars align with feminist theorizing in their emphasis on the always relational character of our capacities for action; the constructed nature of subjects and objects, resemblances and differences; and the corporeal grounds of knowing and action.

The body of relevant work is too extensive to be comprehensively reviewed, but a few indicative examples can serve as illustration. Ethnomethodological studies since the 
1980 s make up one line of such investigations. ${ }^{3}$ An exemplary case, inspired by feminist theorizing with respect to the relational and corporeal foundations of knowing, is provided by Charles Goodwin's analyses of what he terms 'professional vision' (1994) Goodwin's approach is developed in a series of studies focused on the social and material interactions through which practitioners learn to see those phenomena that constitute the objects of their profession. A central argument is that these phenomena are not pre-existing, but are constituted as disciplinarily relevant objects through occasioned performances of competent seeing. It is important to note that 'seeing' for Goodwin is

far from a narrowly scopic or perceptual event, but is rather an activity entailing complex, multisensory embodiments. Goodwin analyses archeological knowledge, for example, as relations between particular, culturally and historically constituted practices and their associated materials and tools. It is out of those relations, quite literally, that the objects of archeological knowledge and the identity of competent archeologist are co-constructed. As a simple case, Goodwin describes how archeologists in the field use a particular artifact, the Munsell chart of universal color categories, to code color features of dirt in an archaeological site (see also Latour 1999:58-61). They do this by taking a trowel of dirt, wetting it, and holding it behind holes cut in the chart. This practice displays both the artfulness of the color chart's design and the ways in which its use presupposes the embodied juxtaposition and skilled reading of dirt in relation to chart. Goodwin also describes the problems of actually using the chart (the colors of real dirt, of course, never quite match these ideal types) and its role in bringing archeologists' perception into the service of a particular organizational/bureaucratic endeavor, that is, professional archaeology.

Other studies have developed these ideas in relation to contemporary work environments, including medicine. As one illustrative case in point, Dawn Goodwin (2004) mobilizes actor network tropes in a close study of the practices through which patients in surgery are 'transitioned' through anaesthetic states, a process involving the radical and progressive reconfiguration of their capacity for action - specifically, for the sustenance of their own life support - through complex arrangements of medical practitioners, machines, routines and other devices. She argues that questions of agency are crucial both to assess policy with respect to medical practice, and to deepen our understanding of the complex sociotechnical arrangements that comprise much of contemporary medical activities and institutions. Through a series of cases she demonstrates how the technologies of anaesthesia are joined to the patient's body, in ways that render the latter highly dependent and vulnerable, but nonetheless intensely (albeit sometimes ambiguously) communicative. This joining is analyzed as a delicate choreography involving patients, medical practitioners and machines. ${ }^{4}$ Over the course

${ }_{3}$ Despite ethnomethodology's troubled relation to feminism, I would argue that the former's commitments to respecifying social order as an embodied, interactional, and irreducibly collaborative achievement (even in the production of individuals and differences) provide deep lines of generative connection. For an early ethnomethodological study of the performativity of sex/gender see Garfinkel 1967, chapter 5. See also Smith 1999.

${ }_{4}$ The phrase 'ontological choreography' was coined by Charis Thompson (Cussins 1998), whose work I return to below. 
of an anaesthesia, agencies involved in the sustenance of vital bodily functions are progressively delegated from 'the patient' as an autonomously embodied entity, to an intricately interconnected sociomaterial assemblage, and then back again. The particular expertise of the anaesthetic practitioner on this account is to manage the often unruly contingencies of the unfolding course of anaesthesia, through a combination of skillfully embodied techniques, reading of signs, professional judgments and legitimating accounts, which together provide the grounds for practical action. Normative prescriptions of correct procedure and power-differentiated divisions of labour complicate the process in ways that can work to undermine the legitimacy of other forms of 'evidence', thereby jeopardizing rather than ensuring safe and effective practice. In this she offers an alternative reading to Poovey (1987) who suggests that anaesthesia administered to ease the pain of childbirth during the Victorian period 'silenced' the female body.

In a related argument developed through the case of reproductive technoscience, feminist science studies scholar Charis Thompson (Cussins 1998) argues against the idea that medical interventions inherently objectify patients and thereby strip them of their agency. She observes that in the case of infertility clinics "the woman's objectification, naturalization, and bureaucratization involve her active participation and are managed by herself as crucially as by the practitioners, procedures, and instruments" (167). Conversely, objectification does not inherently or necessarily lead to alienation, nor does it stand always in opposition to subjectivity or personhood. Among other things, the clinic relies on the possibility of separation (of egg and sperm from the bodies that produce them) without alienation. Cussins locates alienation not in objectification per se, but in the breakdown of synechdochal relations between parts and whole that make objectification of various forms into associated forms of agency. It is this process "of forging a functional zone of compatibility that maintains referential power between things of different kinds" that she names ontological choreography (192). Medical ethics and accountability, she argues, need to be founded not in the figure of the rational, informed citizen but in the conditions for the maintenance of those crucial relations that configure identities and selves, and that might allow them to be reconfigured in desired ways.

The trope of configuration animates another study of surgical practices by Margun Aanestad (2003), who focuses on the labors (carried out predominately by women) involved in aligning a complex sociotechnical environment for the conduct of so-called 'minimally invasive' or 'keyhole' surgery. The latter requires, among other things, displacing the direct gaze of the surgeon and attendant practitioners from the interior of the patient's body - formerly achieved only through a correspondingly large incision - to a view mediated through camera and video monitors. Aanestad's analysis follows the course of shifting interdependencies in the assemblage, as changes to existing arrangements necessitate further changes through what she names the in situ work of "design in configuration" (2). She emphasizes that, in contrast to views of technology design as the province of (predominately male) 'inventors' located in research and development labs, the ongoing work of design takes place in the worksite, and is accomplished by actors rarely recognized as designers.. Moreover, her analysis makes clear again how in such a setting the capacity for action is relational, dynamic and collective rather than inherent in specific network elements, and how the extension of the network in turn intensifies network dependencies. Her analysis has directly gendered implications as well, as the work of nurses, overwhelmingly women, is literally as well as figuratively marginalized in the views of the operating theatre, at the same time that their 
role in the theatre's configuration becomes more central.

The feminist orientations of these studies add crucial sensibilities to the reconceptions of agency under development in STS more broadly. First, feminist research displaces traditional preoccupations with abstracted and decontextualized forms of knowledge in favor of particular, specifically situated practices of knowing in action. Second, feminism directs attention always to the labors (particularly those previously ignored) that are an essential and ongoing aspect of sociotechnical assemblages and the capacities for action that they enable. And finally, feminist research orients us not only to relations and symmetries among persons and things, but also to the politics of difference. The boundaries that constitute things as separate and different are treated not as pregiven, but as enacted, and practices of boundary-making and the enactment of difference are inevitably political.

To reconcile the constructivism of STS with a feminist emphasis on corporeality and the politics of difference, feminist philosopher and physicist Karen Barad has proposed a form of materialist constructivism that she names "agential realism." (2003). Her interest as a physicist is specifically in exploring how subjects and objects can be understood not as separate entities that come together, but as emerging through particular encounters of persons and things. In this, Barad's writings join other feminist scholars working towards conceptualizations of the material that incorporate both obduracy and contingency, symbolic and the material. More specifically, Barad locates scientific practice as a critical site for the emergence of new subjects and objects. Taking physics as a case in point, her project is to work through longstanding divisions between the conceptual and the real, while simultaneously coming to grips with the ways in which materialities, as she puts it, "kick back" in response to our engagements with them (1998:112). Through her readings of Niels Bohr, Barad insists that 'object' and 'agencies of observation' form a nondualistic whole: it is that relational entity that comprises the objective 'phenomenon' (1996: 170). Different "apparatuses of observation" enable different, always temporary, subject/object cuts that in turn enable measurement or other forms of objectification, distinction, manipulation and the like within the phenomenon. The relation is "ontologically primitive" (2003: 815), in other words, or prior to its components; the latter come about only through the 'cut' effected through a particular apparatus of observation. One consequence of this position is a more radical understanding of the sense in which

materiality is discursive (i.e., material phenomena are inseparable from the apparatuses of bodily production: matter emerges out of and includes as part of its being the ongoing reconfiguring of boundaries), just as discursive practices are always already material (i.e., they are ongoing material (re)configurings of the world) (2003: 822).

Brought back into the world of technology design, this intimate co-constitution of configured materialities with configuring agencies clearly implies a very different understanding of the 'human-machine interface'. Read in association with the empirical investigations of complex sites described above, 'the interface' on the one hand becomes the name for a category of contingently enacted 'cuts' occurring always within sociomaterial practices, that effect 'persons' and 'machines' as distinct entities, and that in turn enable particular forms of subject/object intra-actions. At the same time, the 
singularity of 'the interface' explodes into a multiplicity of more and less closely aligned, dynamically configured moments of encounter between other sociomaterial configurations, objectified as persons and machines. It is the differences effected within such configurations that I turn to next. 


\section{Politics of difference}

The reconstructions of sociomaterial agency reviewed above are frequently summarized by the proposition that humans and artifacts are mutually constituted. This premise of technoscience studies has been tremendously valuable as a corrective to the entrenched Euro-American view of humans and machines as autonomous, integral entities that must somehow be brought together and made to interact. But at this point I think the sense of mutual constitution warrants a closer look. In particular, we are now in a position to elaborate that generative trope along at least two critical dimensions: first, in relation to the dynamic and multiple forms of constitution that are evident in specific sociomaterial assemblages (as indicated in the examples of the last section), and second, in terms of the politics of difference within those assemblages.

A case in point of the politics of difference within sociomaterial assemblages is offered by Chasin (1995), who explores identifications across women, servants and machines in contemporary robotics. ${ }^{5} \mathrm{Her}$ aim is to trace the relations between changes in forms of machinic (re)production (mechanical to electrical to electronic), types of labor (industrial to service), and conceptions of human-machine difference. Figured as servants, she points out, technologies reinscribe the difference between 'us' and those who serve us, while eliding the difference between the latter and machines: "The servant troubles the distinction between we-human-subjects-inventors with a lot to do (on the one hand) and them-object-things that make it easier for us (on the other)" (1995: 73).

Domestic service, doubly invisible because a) it is reproductive and b) it takes place in the household, is overwhelmingly provided by people - and of those predominately women - who are displaced and desperate for employment. The latter are, moreover, positioned as 'others' to the dominant (typically white and affluent, at least in North America and Europe) populace. Given the undesirability of service work, the conclusion might be that the growth of the middle class will depend on the replacement of human service providers by 'smart' machines. Or this is the premise, at least, promoted by those who are invested in the latter's development (see Brooks 2002). The reality, however, is more likely to involve the continued labors of human service providers:

in, and following, the era of Reagan-Bush economics, in which the middle class has actually shrunk, and the upper and lower classes have polarized, the number of electronic household appliances has risen with - rather than caused a diminishment of - the number of domestic workers. In this climate, electronics stabilize the idea that a service class of being(s) is proper and even necessary; here, electronics participate in, and thereby reinforce, the unequal social and psychological dynamics upon which the myth of a constantly expanding middle class depends (Chasin 1995: 93).

${ }_{5}$ The dream of machines as the new servant class comprises a translation from the robot visions of the industrial age to that of the service economy. This vision is clearly presented in innumerable invocations of the future of human-computer interactions, perhaps most notably by Brooks, 2002. For further critical discussions see Gonzalez, 1995; Markussen, 1995; Turkle, 1995: 45; Suchman, 2003. 
Chasin poses the question (which I return to below) of how a change in our view of objects from passive and outside the social could help to undo the subject/object binary and all of its attendant orderings, including for example male/female, or mental/manual. Moreover, given the nonexistence of an unmarked, universal 'human' identity, the performance of humanness inevitably entails marks of class, gender and nationality (at the least in terms of language groups). Finally, the 'smart' machine's presentation of itself as the always obliging, 'labor-saving device' erases any evidence of the labor involved in its operation "from bank personnel to software programmers to the third-world workers who so often make the chips" (75). Yet as Ruth Schwartz Cowan (1983) and others since have demonstrated with respect to domestic appliances, the effectiveness of the latter both presupposes and generates new forms of human labor.

\section{Reconceptualising agencies at the human-machine interface}

In the closing chapter of Cyberfeminism and Artificial Life (2003) Sarah Kember asks: "So how should feminists contest the material and metaphoric grounds of human and machine identities, human and machine relations?" (p. 176). In the remainder of this chapter I offer some at least preliminary responses to that question, based in recent efforts to reconfigure agencies at the human-machine interface, both metaphorically and materially, in ways informed by feminist theorizing. As feminist theorists trace a new path across the problematic terrain of how the gendered subject might be reconceived, they alsoprovide us with resources for reconceptualizing the object. Feminist re-theorizing of the body has been concerned to restore the dynamism emptied out of bodies by the mind/body split, precisely by moving through that split to some new terrain. In a similar way, I suggest, we might find other grounds for understanding our relations to the material than the operations of a transcendental intelligence over inert, mechanistically animated matter. As Butler famously puts it in Bodies that Matter:

What I would propose ... is a return to the notion of matter, not as site or surface, but as a process of materialization that stabilizes over time to produce the effect of boundary, fixity, and surface we call matter ... Crucially, then, [the construction of bodies] is neither a single act nor a causal process initiated by a subject and culminating in a set of fixed effects (1993:9-10).

Butler's argument that sexed and gendered bodies are materialized over time through the reiteration of norms is suggestive for a view of technology construction as a process of materialization through a reiteration of forms. Butler argues that 'sex' is a dynamic materialization of always contested gender norms: similarly, we might understand 'things' or objects as materializations of more and less contested, normative identifications of matter. Much as recognition and intelligibility are central to feminist conceptions of the subject, objects achieve recognition within a matrix of historically and culturally constituted familiar, intelligible possibilities. Technologies are both produced and destabilized in the course of these reiterations.

To make this last proposal more concrete, I turn to several examples of what we might characterize as configurations of agency at the human-machine interface, but 
conceptualized in a very different way. The first, and most mundane, case is drawn from a study in the area of computer-supported work, in particular, a civil engineer working at a computer-aided design (CAD) workstation (see Suchman 2000). In her analysis of computer-based work, Susanne Bødker (1991) has discussed the shifting movement of the interface from object to connective medium. She observes that when unfamiliar, or at times of trouble, the interface itself becomes the work's object. At other times persons work as she puts it 'through the interface', enacted as a transparent means of engagement with other objects of interest (for example, a text, or an interchange with colleagues). While CAD might be held up as an exemplar of the abstract representation of concrete things, for the practicing engineer the story is more complex. Rather than stand in place of the specific locales - roadways, natural features, built environments, people and politics - of a project, the CAD system connects the experienced engineer sitting at her worktable to those things, at the same time that they exceed the system's representational capacities. The engineer knows the project through a multiplicity of documents, discussions, extended excursions to the project site, embodied labors and accountabilities, and the textual, graphical and symbolic inscriptions of the interface are read in relation to these heterogeneous forms of embodied knowing. Immersed in her work, the CAD interface becomes for the engineer a simulacrum of the site, not in the sense of a substitute for it, but rather of a place in which to work, with its own specific materialities, constraints and possibilities. While lacking any claims to embodiment, affect or sociality in its own right, the CAD interface-in-use is, I would argue, a powerful site of expanded, sociomaterial agency. It suggests a figure of technological agency not in the form of machinic operations conducted independently of the human, but in the form of a particular configuration, a specifically enacted site of extended, heterogeneously constituted human/nonhuman capacities for thought and action.

Feminist film theorist Laura Marks describes what she calls "haptic visuality" as comprising "images that encourage a sympathy, intimacy and complicity between work and viewer" (2002:x). She uses the term 'work' in this context not with reference to a fetishized object resulting from cinematic practice, but as an always only partially representable complex of social and material labors. Such works effect what Marks' calls a "three-dimensional intimacy" among persons, images and their materiality, and the worlds to which the images connect. Those intimacies, in turn, dissolve the space between object and subject, evoking an embodied response that is more a form of inhabiting the cinematic work than a distanced appraisal of it.

Central to such affective effects are the specific materialities of the medium. Marks observes that in the early days of cinema filmmakers demonstrated their fascination with the new medium's materialities as much as with its abstract representational power. Seen from this perspective, film is not a neutral conveyor of images, but rather the particular qualities of film stock are themselves an integral part of the imagery and imaginary created. It is not only the film's materialities, moreover, that this approach is aimed to recover but also "the rarely acknowledged workers who toil behind the scenes" (ibid: $x$ ). Viewing film is not then a matter of observer and image, but an encounter among the efforts and effects of specifically situated persons and things.

New media artist Heidi Tikka, in her work titled 'Mother, Child', provides a further example. This work, which I had the opportunity to experience during its exhibition at the Art Gallery of Ontario in Toronto, Canada in 2001, employs the shifting dynamics of installation, viewer/user, and onlookers, as well as the ambient environment of the 
exhibition space to invoke, and affectively evoke, an encounter between caregiver and infant. The piece does this not 'in general', but always specifically: the caregiver is one, particular person who enters the space of the installation and sits on a chair, the infant is one, particular infant (Tikka's son, recorded on digital video). A distinguishing aspect of the piece is the heterogeneity of its forms: real bodies and objects combine with projected images to comprise a hybrid of social and material elements. Together these elements create an interactive space characterized by a mix of predictability and contingency - a fragile stability - which affords the installation its affective kinship to the 'real world' encounter that it simulates. The three-dimensional image of a child that is 'projected' both technically and psychically - onto the soft cloth diaper that the viewer/user holds in her lap can be affected through her motions and orientation to it, but dissolves as she stands and places the cloth back onto the chair. In this and other ways, the installation continually reminds us of, rather than conceals, its artifice. As Tikka herself comments, the piece is actually simpler, less reactive in its composition than we experience it to be. The effects are created through the particular possibilities provided by an artful integration of persons, objects, spaces, fantasies, remembered experiences and technologies to evoke and explore an emblematically human encounter, but not to replicate it.

\section{Expanding frames and accountable cuts}

I take an identifying commitment of feminist research to be a deepened appreciation of the relational foundations not only of social worlds but also of material realities. While this is an interest shared by others within STS and contemporary social, feminist research further contributes a critical orientation of the politics of difference, combined with forms of constructive engagement aimed at more just distributions of symbolic and economic reward. In "Getting Real," Barad proposes that "reality is sedimented out of the process of making the world intelligible through certain practices and not others ..." (1998: 105). If, as Barad and other feminist researchers suggest, we are responsible for what exists, what is the reality that current discourses and practices regarding new technologies make intelligible, and what is excluded? To answer this question Barad argues that we need a simultaneous account of the relations of humans and nonhumans and of their asymmetries and differences. This requires remembering that boundaries between humans and machines are not naturally given but constructed, in particular historical ways and with particular social and material consequences. As Barad points out, boundaries are necessary for the creation of meaning, and, for that very reason, are never innocent. Because the cuts implied in boundary making are always agentially positioned rather than naturally occurring, and because boundaries have real consequences, she argues, "accountability is mandatory" (187). :

We are responsible for the world in which we live not because it is an arbitrary construction of our choosing, but because it is sedimented out of particular practices that we have a role in shaping (1998: 102).

The accountability involved is not, however, a matter of identifying authorship in any simple sense, but rather a problem of understanding the effects of particular assemblages, and assessing the distributions, for better and worse, that they engender. Responsibility on this view is met neither through control nor abdication, but in ongoing practical, critical, 
and generative acts of engagement.

In the case of responsibility for new technologies, Andrew Barry (1999) draws a useful distinction between 'novelty' and 'invention,' and argues that there is no simple relation between the speed with which new things are produced, and inventiveness. In contrast to the premise that innovation can be measured in terms of the number of ideas that are locked in place through their materialization as patented artifacts, Barry proposes a view of inventiveness as "an index of the degree to which an object or practice is associated with opening up questions and possibilities ... what is inventive is not the novelty of artefacts in themselves, but the novelty of the arrangements with other activities and entities within which artefacts are situated. And might be situated in the future" (p. 4). He suggests further that there might actually be an inverse relation between the speed of change, and the expansion of inventiveness - that "moving things rapidly may increase a general state of inertia; fixing things in place before alternatives have the chance of developing" (p. 6). I have made a similar argument (Suchman 1999) with respect to technology innovation under the banner of 'artful integration,' attempting to shift the frame of design practice and its objects from the figure of the heroic designer and associated next new thing, to ongoing, collective practices of sociomaterial configuration, and reconfiguration in use.

With this argument in mind, I want to close by offering a final example that serves I think as a kind of pointer to a different conception of practices of innovation as the ongoing and everyday. My former colleague at Xerox's Palo Alto Research Center and accomplished computer scientist, Randall Trigg, has left the circuits of 'world class' research and development to become what he describes as the 'de facto IT department' for an organization devoted to making new circuits through which worldwide resources might flow. The organization, the Global Fund for Women (GFW), serves as a redistribution point for U.S. wealth, providing micro grants to grassroots women's organizations in other parts of the world. The Fund itself is distinguished by its extraordinarily local/global networked form, where former grantees become the sites through which new micro grants are distributed. Technology design at the Fund involves ongoing co-development, with others in the GFW headquarters and among their grantees, of an information and communications infrastructure to support this local/global network. In considering this work it would be difficult to isolate singular achievements of the 'new'. And yet together, over time and space, I would argue that it is labors like this that represents our best hope for genuinely new reconfigurings of the technological, based not in inventor heroes or extraordinary new devices, but in mundane, and innovative, practices of collective sociomaterial infrastructure building.

\section{References}

Aanestad, M. (2003) The camera as an actor: Design-in-use of Telemedicine Infrastructure in Surgery. Computer-Supported Cooperative Work (CSCW) 12: 1-20.

Ahmed, Sara (1998) Diferences that Matter: Feminist Theory and Postmodernism. Cambridge, UK: Cambridge University Press.

Ahmed, Sara (2000) Strange encounters: embodied others in post-coloniality. London ; New York: Routledge. 
Ashmore, Malcolm, Wooffitt, Robin and Harding, Stella (1994) Humans and Others: the Concept of 'Agency' and its Attribution. American Behavioral Scientist.

Balsamo, Anne Marie (1996) Technologies of the gendered body: reading cyborg women. Durham: Duke University Press.

Barad, Karen (1996) Meeting the Universe Halfway: Ambiguities, Discontinuities, Quantum Subjects, and Multiple Positionings in Feminism and Physics. In L. H. Nelson \& J. Nelson (eds.), Feminism, Science, and the Philosophy of Science: A Dialog pp. 161-194. Norwell, MA: Kluwer.

Barad, Karen (1998) Getting Real: Technoscientific Practices and the Materialization of Reality. diferences: A Journal of Feminist Cultural Studies, 10: 88-128.

Barad, Karen (2003) Posthumanist Performativity: Toward and understanding of how matter comes to matter. Signs: Journal of Women in Culture and Society 28: 801831.

Barry, Andrew (1999) Invention and Inertia. Cambridge Anthropology 21.

Berg, Marc and Mol, Annemarie (1998) Diferences in medicine: unraveling practices, techniques, and bodies. Durham, N.C.: Duke University Press.

Bødker, Susanne (1991) Through the interface: a human activity approach to user interface design. Hillsdale, N.J.: L. Erlbaum.

Braidotti, Rosi (1994) Nomadic Subjects. New York: Columbia University Press.

Braidotti, Rosi (2002) Metamorphoses: towards a materialist theory of becoming. Cambridge: Blackwell Publishers.

Butler, Judith (1993) Bodies that matter: on the discursive limits of "sex". New York: Routledge.

Brooks, Rodney (2002) Flesh and machines: how robots will change us. New York: Pantheon Books.

Castañeda, Claudia (2002) Figurations: Child, Bodies, Worlds. Durham and London: Duke.

Chasin, Alexandra (1995) Class and its Close Relations: Identities among women, servants, and machines. In J. Halberstram \& I. Livingston (eds.), Posthuman Bodies pp. 73-96. Bloomington: Indiana University Press.

Clement, Andrew 1993 Looking for the Designers: Transforming the 'invisible' infrastructure of computerized office work. In AI \& Society, Special Is sue on Gender, Culture and Technology, 7:323-344.

Cussins, Charis (1998) Ontological Choreography: Agency for women patients in an infertility clinic. In M. Berg \& A.-m. Mol (eds.), Diferences in Medicine pp. 166201. Durham, NC: Duke University Press. 
Fujimura, Joan. 1987. Constructing 'Do-able' Problems in Cancer Research: Articulating Alignment. Social Studies of Science 17:257-93.

Garfinkel, Harold (1967) Studies in ethnomethodology. Englewood Cliffs, N.J.: PrenticeHall.

Gonzalez, Jennifer (1995/2000) Envisioning Cyborg Bodies: Notes from Current Research. In G. e. a. Kirkup (ed.), The Gendered Cyborg pp. 5 8-73. New York and London: Routledge.

Goodwin, Charles (1994) Professional Vision. American Anthropologist 96: 606-633.

Goodwin, Dawn (2004) Acting in Anaesthesia: Agency, participation and legitimation. Unpublished Ph.D., Lancaster University.

Gupta, Akhil and Ferguson, James (1997) Culture, Power, Place: Explorations in Critical Anthropology. Durham, NC: Duke.

Haraway, Donna (1985/199 1) A Manifesto for Cyborgs. In Simians, cyborgs, and women: the reinvention of nature. New York: Routledge. Originally published in Socialist Review (1985) 80: 65-108.

Kember, Sarah (2003) Cyberfeminism and Artificial Life. London \& New York: Routledge.

Latour, Bruno (1999) Pandora's hope: essays on the reality of science studies. Cambridge, Mass.: Harvard University Press.

Law, John (1994) Organizing modernity. Oxford, UK ; Cambridge, Mass., USA: Blackwell.

Law, John and Mol, Annemarie (2002) Complexities: Social Studies of Knowledge Practices. Durham and London: Duke.

Marks, Laura U. (2002) Touch: sensuous theory and multisensory media. Minneapolis: University of Minnesota Press.

Markussen, Randi (1995) Constructing easiness - historical perspectives on work, computerization, and women. In S. L. Star (ed.), Cultures of Computing. Oxford: Blackwell.

Poovey, Mary (1987) "Scenes of an indelicate character": the medical "treatment" of victorian women. In Gallagher, $\mathrm{C}$ and Lacqueur, $\mathrm{T}$ (Eds) The Making of the Modern Body: Sexuality and Society in the Nineteenth Century. Berkeley: University of California Press. Pp 137-168.

Schmidt, Kjeld and Bannon, Liam(1992) Taking CSCW Seriously: Supporting Articulation Work. Computer-Supported Cooperative Work (CSCW), Vol., 1, Nos. 1-2: 7-40.

Shapin, Steve (1989) The invisible technician. American Scientist 77: 553-63.

Smith, Dorothy E. (1999) Writing the social: critique, theory, and investigations. Toronto: University of Toronto Press.

Star, Susan Leigh (1991) Invisible Work and Silenced Dialogues in Knowledge Representation. In Women, Work and Computerization, eds. I. Eriksson,B. Kitchenham, and K. Tijdens, K., 8 1-92. Amsterdam: North Holland. 
Strathern, Marilyn (1999) Property, substance, and efect : anthropological essays on persons and things. London; New Brunswick, NJ: Athlone Press.

Suchman, Lucy and Brigitte Jordan (1989) Computerization and Women's Knowledge. In Women, Work and Computerization, eds. K. Tijdens, M. Jennings, I. Wagner and M. Weggelaar, 153-160. Amsterdam: North Holland.

Suchman, Lucy (1987) Plans and Situated Actions: the problem of human-machine communication. New York: Cambridge University Press.

Suchman, Lucy (1999) Working Relations of Technology Production and Use. In D. Mackenzie \& J. Wajcman (eds.), The Social Shaping of Technology, Second Edition pp. 258-68. Buckingham and Philadelphia: Open University.

Suchman, Lucy (2000) Embodied Practices of Engineering Work. Mind, Culture \& Activity 7: 4-18.

Suchman, Lucy (2002a) Located Accountabilities in Technology Production. Scandinavian Journal of Information Systems 14: 9 1-105.

Suchman, Lucy (2002b) Practice-based Design: Notes from the hyper-developed world. The Information Society 18: 1-6.

Suchman, Lucy (2003) Figuring Service in Discourses of ICT: The case of software agents. In E. e. a. Wynn (ed.), Global and Organizational Discourses about Information Technology pp. 15-32. Dordrecht: the Netherlands: Kluwer.

Suchman, Lucy (forth) Plans and Situated Actions I: human-machine Reconfigurations. $2_{\text {nd }}$ Edition. New York and Cambridge, UK: Cambridge University Press.

Turkle, Sherry (1995) Life on the screen: identity in the age of the Internet. New York, Toronto: Simon \& Schuster.

Verran, Helen (2001) Science and An African Logic. Chicago: University of Chicago. 